Article

\title{
Computational and experimental analysis of reinforced aerated concrete beam concrete containing rice husk ash
}

\author{
Muhammad Tahir Lakhiara, ${ }^{a}$, Ather Ali b, Kong Sih Yinga, Muhammad Tarique Lakhiarc \\ aSchool of Engineering, Monash University Malaysia \\ b School of Civil and Environmental Engineering, National University of Science and Technology, Pakistan \\ c Faculty of Civil and Built Environment, Universiti Tun Hussein Onn Malaysia \\ * Correspondence: muhammad.lakhiar"monash.edu;
}

\begin{abstract}
Aerated concrete, which is manufactured from binding material, sand, foaming agent and water, is currently being utilized in the construction industry because of its lightweight and durability. The binding material, cement, along with other materials used in the concrete produces huge carbon footprints during its fabrication. The utilization of natural aggregates name as coarse aggregates depletes the natural resources of the country. Therefore, huge amounts of agricultural wastes have led scholars to investigate the effectiveness of replacing conventional materials used in concrete with agricultural wastes. In the current study, rice husk ash (RHA) was used as supplementary cementing material, thereby reducing the amount of cement used in aerated concrete $(\mathrm{AC})$ mixture will reduce carbon footprints. The experimental and numerical analysis were conducted to investigate structural behavior of reinforced RAC- B beams subjected to flexural load. Parametric study on structural performance of RAC- B beam under flexure were conducted using finite element analysis (FEA). From the experiment and FEA. Results from the parametric study showed that RAC-10\%RHA-B with higher depth structurally performed better compared to RAC$\mathrm{B}$ under flexure with greater load carrying capacity, lesser maximum deflection, and less cracks developing in the tension area.
\end{abstract}

Keywords: Aerated concrete, ultimate load, finite element analysis and rice husk ash.

\section{Introduction}

At present, construction industry mostly utilizes concrete to manufacture structural members. Concrete serves great application purposes in construction industry such as, construction of skyscrapers, bridges, water reservoirs, highways and buildings [1-3]. The rapid development of construction industry raises the demand for concrete due to its high strength, durability, on-site molding ability, and better economy in comparison with other building materials [4-5].

Researchers have investigated various kinds of concrete in the past such as, self-compacting concrete, conventional concrete and foamed or aerated concrete. Aerated concrete has a dry density of 300 to $1800 \mathrm{~kg} / \mathrm{m} 3$, which is $85 \%$ lighter than the conventional concrete and falls under the category of Lightweight concrete [6-7]. To reduce the density of concrete, air-voids are introduced by utilizing a foaming agent during concrete manufacture [8]. Aerated concrete is primarily used in the construction of non-structural elements to reduce structural loads [9]. Aerated concrete is manufactured from binding material, foaming agent and sand. Binding material such as cement is greatly used in all kinds of concrete to bind all other constituent materials together to give high strength and hardness. Besides that, the manufacturing of cement creates huge number of environmental problems [10-11]. Cement industry is the source for the release of $10 \%$ of the total 
global carbon dioxide $\left(\mathrm{CO}_{2}\right)$ emissions. $\mathrm{CO} 2$ emissions are highly detrimental for the ozone layer and leads to global warming and climate changes [12-13]. To over this problem great number of researchers are working to introduce the new innovative binding material.

Meanwhile, agricultural solid waste created from residential area, commercial business and institutions is increasing daily. Nowadays 1.3 billion tons per annum global municipal solid waste is produced due to rise in population and enhancement in standard of living, approximately 1.2 $\mathrm{kg} / \mathrm{capita} /$ day municipal waste is produced, but it increases to $1.42 \mathrm{~kg} / \mathrm{capita} /$ day in 2020 [14]. One of the attractive solutions to overcome this issue is to recycle the agricultural waste and utilize it as binding material or admixtures to enhance the mechanical properties of concrete. Rice husk ash, Sugar cane bagasse ash, egg shell ash and banana skin powder could be used as partial replacement of cementing material [15].

Experimental analysis of structural member is time, energy and material consuming due to that in this research, reinforced aerated concrete beam model containing RHA was analysed by FEA software package name as ABAQUS explicit under flexural load because it requires less disk space and memory than Abaqus/Standard for the same simulation. For problems in which the computational cost of the two programs may be comparable, the substantial disk space and memory savings of Abaqus/Explicit make it attractive. Subsequent parametric study by changing shear span over depth ratio was conducted and the outcomes from FEA were validated with the experimental and literature studies.

\section{Materials and Methods}

The experimental analysis of RAC beam contains the following steps:

Specify the beam dimensions, fabrication, and casting, curing and testing under four-point loading condition.

\subsection{RAC-B specifications}

The aim of this study is to investigate the structural performance of RAC-B interms of load deflection, ultimate load and cracking pattern. RAC-B was casted by using $0 \%$ and $10 \%$ RHA as cement replacement.

RAC-B having $1600 \mathrm{~mm}$ total length and rectangular cross sectional width of $100 \mathrm{~mm}$ and a depth of $200 \mathrm{~mm}$ were used in this research.

Formwork for RAC- B was prepared by using $10 \mathrm{~mm}$ thick plywood sheet. The fine aggregate (sand) was properly dried to avoid any influence on water binder ratio. The RHA used in this study was sieved from 45 micron meter because according to ASTM --- 90\% cement must be sieved from 45 micro meter. The main reinforcement and stirrups were cut into the design lengths as shown in Figure 1.

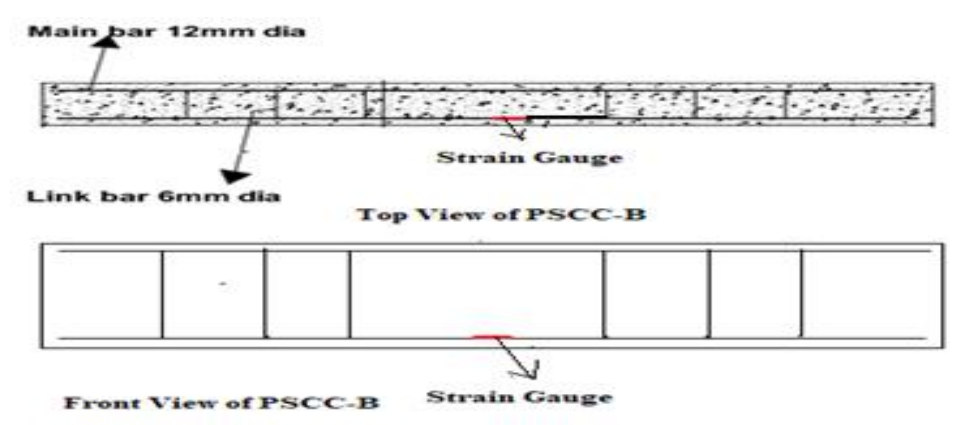


Figure 1. Main reinforcement and stirrups cut into design length

\subsection{Testing of RAC-RHA-B}

The entire test protocol for the RAC-RHA-B beams can be characterized as follows:

- Instrumentation

- Procedure

- Measurement.

\subsubsection{Instrumentation}

Beams were instrumented to sufficiently record their response behavior under flexural loads as shown in Figure 2. The instruments and equipment that were adopted in this study were:

1. Testing rig: Universal Test Frame (AL-3000 MF) of $2500 \mathrm{kN}$

2. Load cell: $1500 \mathrm{kN}$

3. Hydraulic pump: TCLP - 1MNB - D (ALCO)

4. Data logger: TDS - 530 (ALCO)

5. LVDT: $100 \mathrm{~mm}$

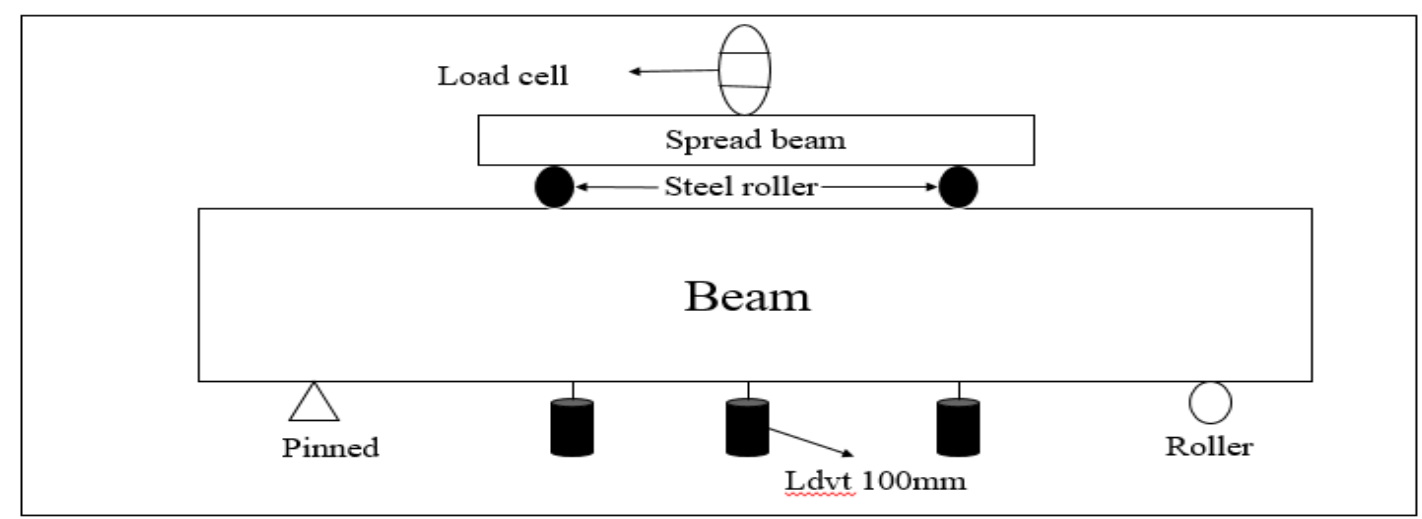

Figure 2. Flexural test setup for beam

\subsubsection{Procedure}

After the installation of instruments, load was constantly applied at the mid-section of the beam and transferred load to beam by load spreader by using manually controlled hydraulic jack with a loading rate of $5 \mathrm{kN} / \mathrm{min}$. The flexural load during the beam testing was recorded by the load cell. A data logger was combined to the load cell to record the applied loading and the corresponding deflections until the beam reached the ultimate failure strength.

\subsubsection{Measurement}

Deflection of the beam was noted by using three linear variable differential transducer (LVDTs) with a gauge length of $120 \mathrm{~mm}$. LVDTs were installed at three different locations, namely, at the mid-span and under the point loading of beam. The base of LVDTs were linked to the steel hooks which were placed at the vertical portion of the beam as the load applied the beam deflect so deflection were recorded as shown in Figure 2. The LVDTs were joint to the data logger to get the deflection data. In this way, the attached data logger was developed initial readings for deflection. The results for deflection of the beam at each incremental load were recorded continuously during the test.

\section{Finite element analysis of RAC-RHA-B}

The three dimensional-nonlinear finite element beam models were modelled by FEA computer based application Abaqus to analyse the performance of beams under flexural loading. 


\subsection{Element kinds of each materials}

RAC-B and RAC-10\%RHA-B were analysed separately, the part of Abaqus module by adopting different kinds of element based on the suitability of each element. The element used for each part are arranged in Table 1 and Table 2, the element type selected for each part are created on the appropriateness and competence of the element type. The modelling procedure for RAC-RHA-B including discretized geometry, element section properties, material data, loading and boundary conditions, analysis types and output are described in next sections.

Table 1. Element used for each part of PSCC beam

\begin{tabular}{llll}
\hline No. & Part & Element & Definition of Element \\
\hline 1 & Aerated concrete & C3D8R & $\begin{array}{l}\text { Continum three dimensional 8 nodes linear } \\
\text { brick element, reduced integration and } \\
\text { hourglass control } \\
\text { Three dimensional 2 nodes truss element }\end{array}$ \\
2 & Main reinforcement & T3D2 & ThD2 \\
\hline
\end{tabular}

The RAC-RHA-B model was initially established with geometric discretization of each part. The steel reinforcement was simulated using three dimensional 2-node elements. The concrete damage plasticity of RAC-B and RAC-10\%RHA-B which were extracted from the experimental outcomes are presented in Table 3. The dilatation angle, eccentricity, initial biaxial/ uniaxial ratio, viscosity were taken from Rahman et al. (2019) [16].

Table 2. The materials properties of RAC-RHA-B

\begin{tabular}{|c|c|}
\hline Mix name & Properties \\
\hline \multirow{6}{*}{$\begin{array}{l}\text { Reiforced Aerated } \\
\text { Concrete Beam ( RAC-B) } \\
\text { (Control Sample) }\end{array}$} & Consists of $100 \%$ of cement, $0 \%$ of RHA. \\
\hline & Mass Density, $\varrho=1600 \mathrm{~kg} / \mathrm{m} 3$ \\
\hline & 28 Days Compression Strength, $\mathrm{fcu}=17 \mathrm{MPa}$ \\
\hline & 28 Days Tensile Strength, fst $=2.1 \mathrm{MPa}$ \\
\hline & Young's Modulus, E = 22.13 GPa \\
\hline & Poisson's Ration, v = 0.11 \\
\hline \multirow{6}{*}{ RAC-RHA-B (10\% RHA) } & Consists of $90 \%$ of cement, $10 \%$ of RHA. \\
\hline & Mass Density, $\varrho=1600 \mathrm{~kg} / \mathrm{m} 3$ \\
\hline & 28 Days Compression Strength, $\mathrm{fcu}=19.2 \mathrm{MPa}$ \\
\hline & 28 Days Tensile Strength, fst $=2.5 \mathrm{MPa}$ \\
\hline & Young's Modulus, E = 24.98 GPa \\
\hline & Poisson's Ration, $\mathrm{v}=0.14$ \\
\hline
\end{tabular}

Table 3. Concrete damaged plasticity of aerated concrete

\begin{tabular}{|c|c|c|c|c|}
\hline \multicolumn{5}{|c|}{ Concrete Damaged Plasticity } \\
\hline $\begin{array}{l}\text { Dilatation } \\
\text { Angle }\end{array}$ & Eccentricity & $\begin{array}{l}\text { Initial biaxial/ uniaxial } \\
\text { ratio, } \sigma \mathrm{c} 0 / \sigma \mathrm{b} 0\end{array}$ & $\mathbf{K}$ & Viscosity \\
\hline $32^{\circ}$ & 1 & 1.13 & 0.6 & 0 \\
\hline \multicolumn{5}{|c|}{ RAC- B } \\
\hline \multicolumn{2}{|c|}{ Compressive Behavior } & \multicolumn{2}{|c|}{ Tensile Behavior } & \\
\hline
\end{tabular}




\begin{tabular}{|c|c|c|c|c|c|}
\hline $\begin{array}{l}\text { Yield } \\
\text { Stress, } \\
\text { (MPa) }\end{array}$ & $\begin{array}{l}\text { Inelastic } \\
\text { Strain }\end{array}$ & $\begin{array}{l}\text { Damage } \\
\text { Parameter }\end{array}$ & $\begin{array}{l}\text { Yield Stress } \\
\text { (MPa) }\end{array}$ & $\begin{array}{l}\text { Cracking } \\
\text { Strain }\end{array}$ & $\begin{array}{l}\text { Damage } \\
\text { Parameter }\end{array}$ \\
\hline 17 & 0 & 0 & 2.1 & 0 & 0 \\
\hline 16 & 0.006370 & 0.1135 & 1.5 & 0.005152 & 0.2812 \\
\hline 15 & 0.010020 & 0.4512 & 1.2 & 0.005914 & 0.5121 \\
\hline 10 & 0.015126 & 0.6314 & 1 & 0.006623 & 0.5975 \\
\hline 7 & 0.021756 & 0.8246 & 0.8 & 0.014362 & 0.8535 \\
\hline \multicolumn{6}{|c|}{ RAC-10\%RHA-B } \\
\hline \multicolumn{3}{|c|}{ Compressive Behavior } & \multicolumn{3}{|c|}{ Tensile Behavior } \\
\hline $\begin{array}{l}\text { Yield } \\
\text { Stress, } \\
\text { (MPa) }\end{array}$ & $\begin{array}{l}\text { Inelastic } \\
\text { Strain }\end{array}$ & $\begin{array}{l}\text { Damage } \\
\text { Parameter }\end{array}$ & $\begin{array}{l}\text { Yield Stress } \\
\text { (MPa) }\end{array}$ & $\begin{array}{l}\text { Cracking } \\
\text { Strain }\end{array}$ & $\begin{array}{l}\text { Damage } \\
\text { Parameter }\end{array}$ \\
\hline 19 & 0 & 0 & 2.5 & 0 & 0 \\
\hline 17 & 0.006580 & 0.1251 & 2.25 & 0.004914 & 0.2942 \\
\hline 14 & 0.014510 & 0.4682 & 2 & 0.005821 & 0.5273 \\
\hline 12 & 0.016325 & 0.6941 & 1.5 & 0.007109 & 0.6172 \\
\hline 9 & 0.025691 & 0.8350 & 2 & 0.018389 & 0.9734 \\
\hline
\end{tabular}

\subsection{Convergence study}

The quasi-static analysis method was further method with different element extents as shown in Tables 4 to demonstrate mesh sensitivity. Similar material characteristics were used for all mesh sizes. Results of the FEA analysis using different mesh density for RAC-B (control sample) are presented in Table 5. Figure 2 demonstrates the effects of mesh sizes on the results of the analysis. The result converged to a near constant value when the number of element reached 15,234. Load versus vertical displacement presented similar behaviour for model with global size 17, 15 and 13 thus the suitable mesh density chosen for parametric study was global size 17 to 13 or about 15,234 to 23,143 elements. The difference in element number was due to size difference of RAC-RHA-B.

Table 4. Result of mesh enhancement study of RAC-RHA-B (Control beam)

\begin{tabular}{llllll}
\hline $\begin{array}{l}\text { Mesh } \\
\text { Size }\end{array}$ & $\begin{array}{l}\text { Total } \\
\text { Elements }\end{array}$ & $\begin{array}{l}\text { Pu } \\
\text { FEA }\end{array}$ & $\begin{array}{l}\text { (kN) } \\
\text { Pu } \\
\text { Experiment }\end{array}$ & $\begin{array}{l}\text { (kN) } \\
\text { \% } \\
\text { Difference }\end{array}$ \\
\hline GB200 & 24 & 71.12 & 42 & $69.33 \%$ \\
GB150 & 28 & 68.19 & 42 & $62.35 \%$ \\
GB100 & 108 & 62.53 & 42 & $47.61 \%$ \\
GB50 & 612 & 59.32 & 42 & $41.23 \%$ \\
GB30 & 2,650 & 55.76 & 42 & $12.69 \%$ \\
GB25 & 4,608 & 50.12 & 42 & $32.76 \%$ \\
GB20 & 9,360 & 48.75 & 42 & $16.07 \%$ \\
GB17 & 15,235 & 44.71 & 42 & $6.45 \%$ \\
GB15 & 18,619 & 44.71 & 42 & $6.45 \%$ \\
GB13 & 23,143 & 44.71 & 42 & $6.45 \%$ \\
Note: GB = global size for mesh density in Abaqus & \\
\hline
\end{tabular}




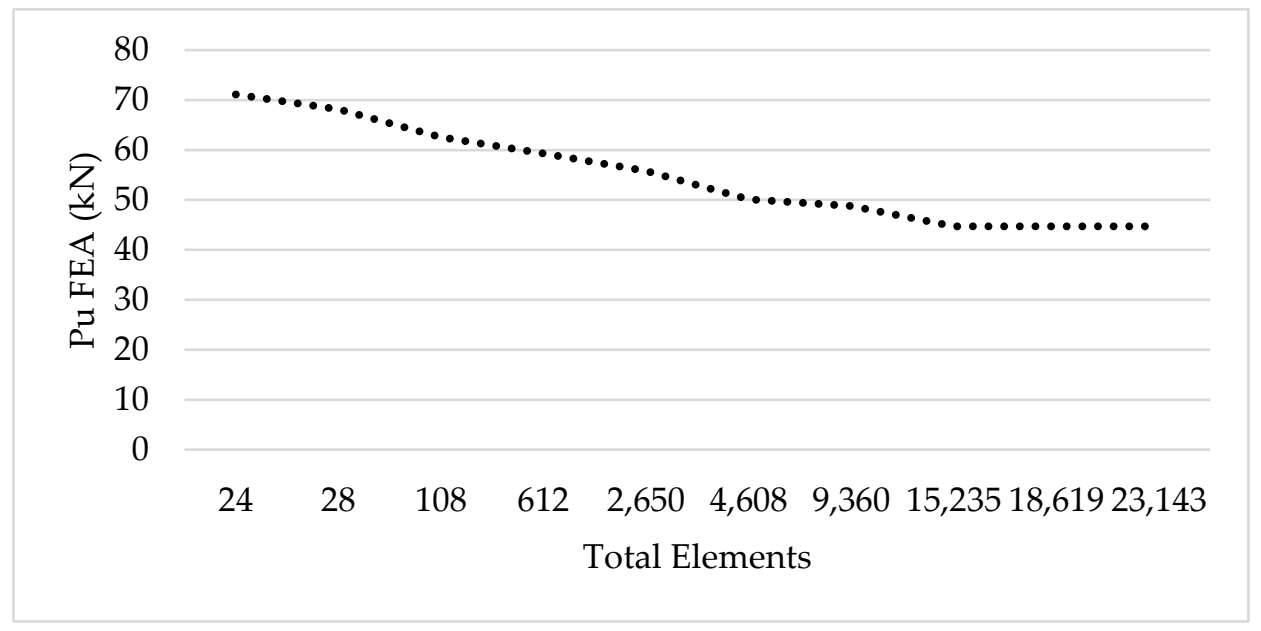

Figure 2. Result of mesh enhancement study of RAC-RHA-B (Control beam)

\subsection{Boundary conditions}

The point load was applied at the top surface of the beams and simply supported boundary conditions were provided at the bottom surface of the beam. After the RAC-RHA-B model was assembled, the discrete modelled section was connected appropriately to each other. Embedded approach was implemented to make appropriate interaction between aerated concrete and steel reinforcement as presented in Figure 3.

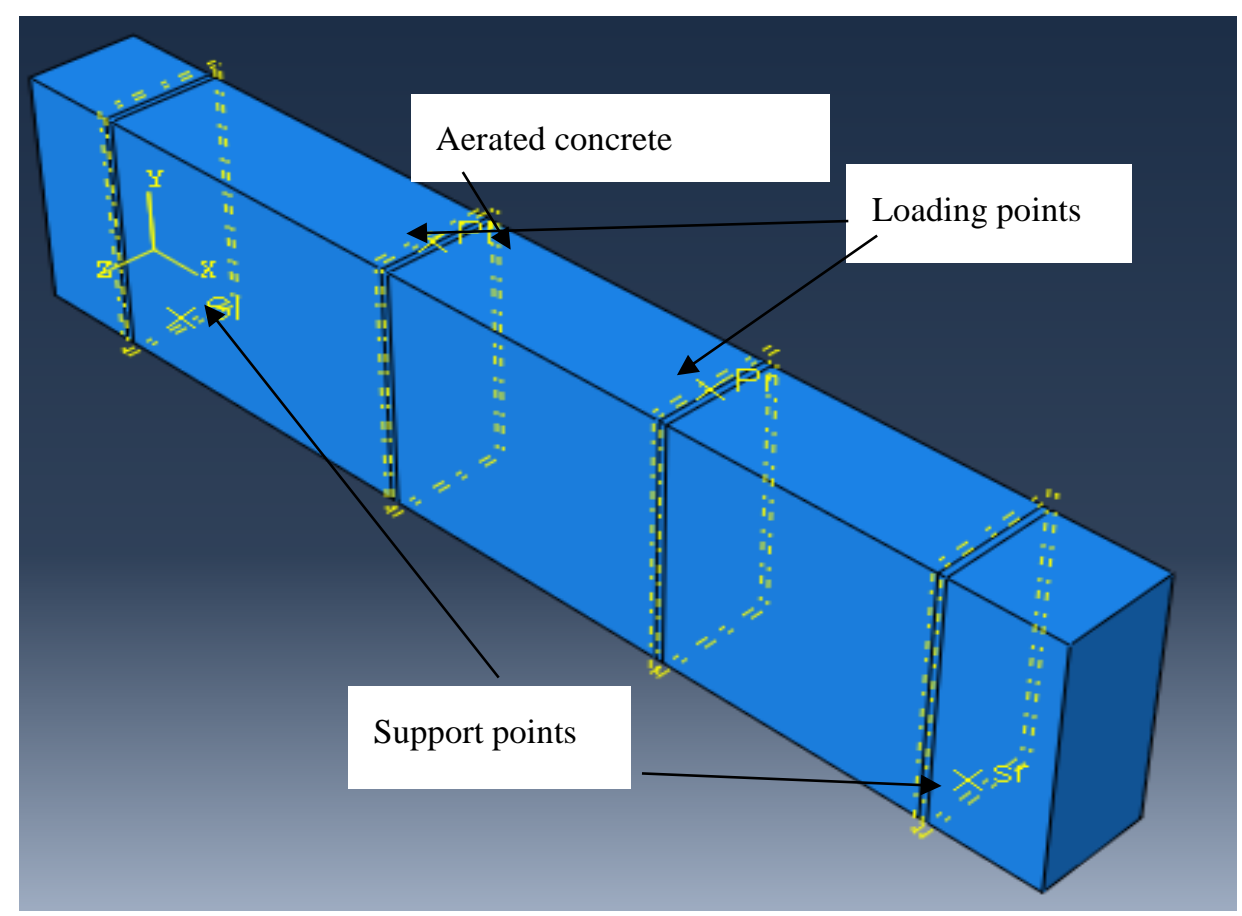

Figure 3. Structural model of PSCC beam

For point line load, displacement was assigned at $\mathrm{Y}$ direction at the reference point on the rigid body to simulate the applied loading on the top of the beam.

From the given vertical displacement, the equivalent loading given on RAC-RHA-B could be found from the history output in the outcome result file. Vertical displacement was rise significantly as the applied force magnitude increases until the beam failed at ultimate load and post failure occurred. 
Finally, the convergence of RAC-RHA-B was observed with mesh sensitivity analysis by changing the mesh density to get the final mesh size for RAC-RHA-B. The critical outcomes parameters from the FEA were validated with the experimental results.

\section{Results and discussions}

The outcomes such as ultimate load, cracking pattern and load deflection profile of RAC-RHA-B from ABAQUS simulation were extracted from post processing and validated with the experimental results.

\subsection{Ultimate load}

The ultimate load, maximum load carried by the beam before failure, obtained from experiment and FEA are shown in Table 5. The results presented in Table 5 show that RAC-10\%RHA-B from experiments and FEA give approximately $18.5 \%$ higher ultimate load than the control sample. In general, FEA outcomes presented higher ultimate load compared to experimental results. This is due to the fact that FEA works under ideal conditions whereas experimental investigations are prone to a variety of external influences. The percentage variation of the ultimate load outcomes from experiments and FEA for all beam samples were documented in the range of $5.88 \%$ to $7.5 \%$. This difference is satisfactory because it is less than $20 \%$ for analysing the structural behaviour of the beam subjected to flexural load. Wang et al., (2018) [17]; Sjaarda et al., (2018)[18] and Murthy et al., (2018) [19], analysed the structural behaviour of reinforced concrete beam by experimental work and FEA. The outcomes demonstrated that the difference between experimental and FEA outcomes were $10 \%$ to $15 \%$.

Table 5. Ultimate load carrying capacity of PSCC beam

\begin{tabular}{|c|c|c|c|}
\hline \multirow[b]{2}{*}{ Beam } & \multicolumn{2}{|c|}{ Ultimate Load (kN) } & \multirow{2}{*}{$\frac{P_{u(F E A)}-P_{u(E X P)}}{P_{u(E X P)}} x 100 \%$} \\
\hline & Experiment & FEA & \\
\hline RAC-B (Control sample) & 34 & 36 & $5.88 \%$ \\
\hline RAC-10\%RHA-B & 40 & 43 & $7.5 \%$ \\
\hline
\end{tabular}

\subsection{Cracking profile of RAC-RHA-B}

The cracking pattern of all RAC-RHA beams from FEA are shown in Figure 4. The failure mode and cracking profile were validated with the experimental outcomes and the previous studies conducted by Vilke et al., (2017) [20]; Wahalathantri et al., (2011) [21] and Sihau et al., (2015) [22], which analysed the cracking pattern of simply supported reinforced concrete beam under point load using Abaqus. The results showed that first crack appeared at the bottom of the beam close to the centre of the span. The cracks appeared at the tension zone and moved towards the compression zone as load increased. The outcomes of cracking pattern of RAC-RHA beams from FEA were found to have similar trends as obtained from the experimental work performed for this study and the previous researches. 


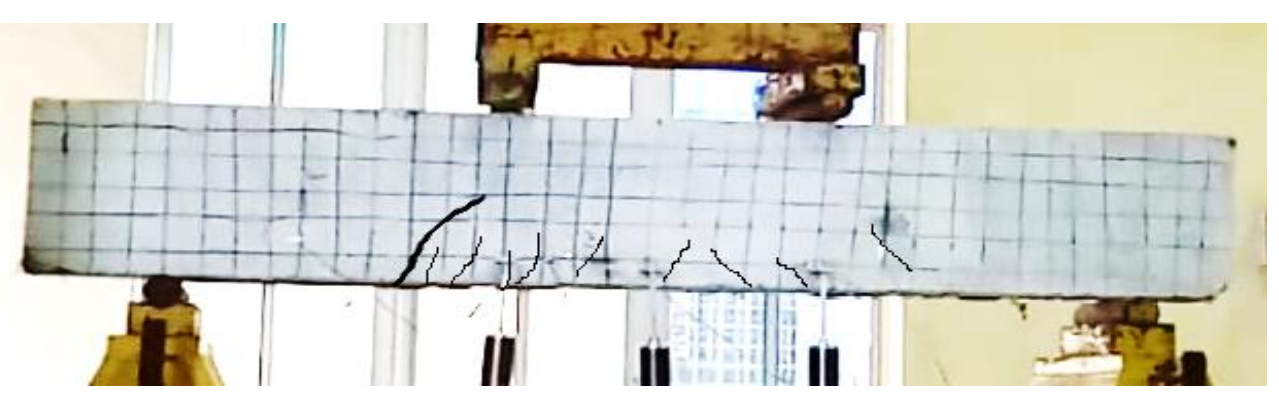

(a) Crack pattern of RAC-B by Experimental

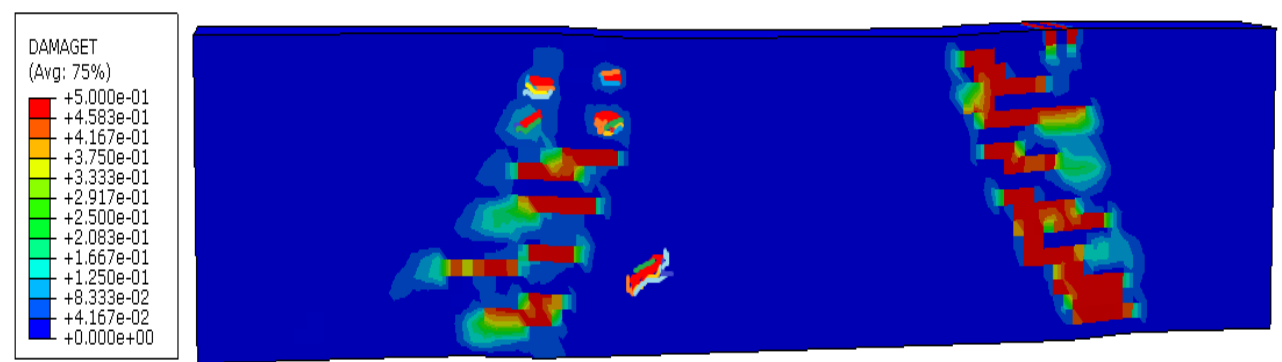

(b)Crack pattern of RAC-B by FEA

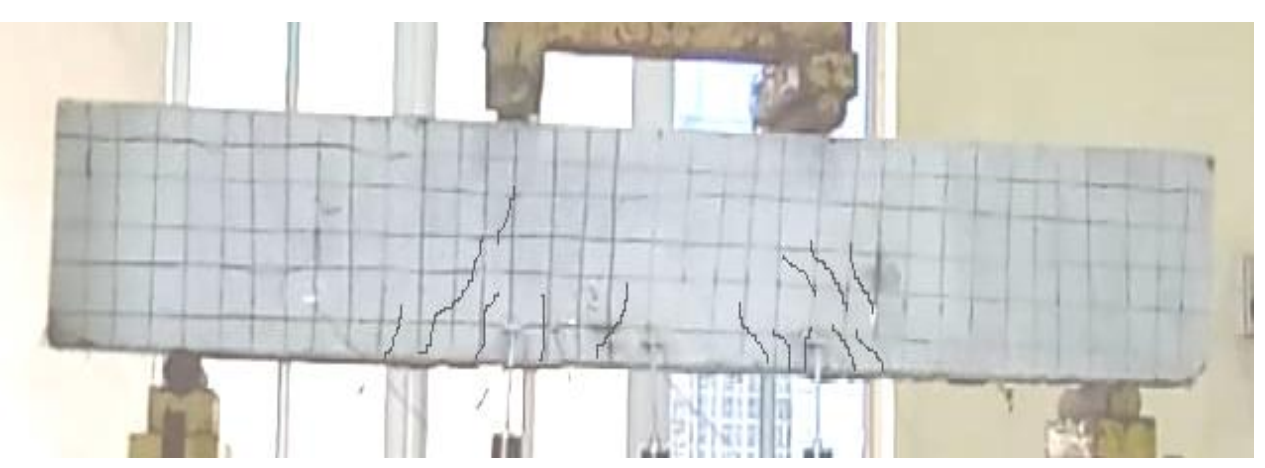

(c)Crack pattern of RAC-10\%RHA-B by Experimental

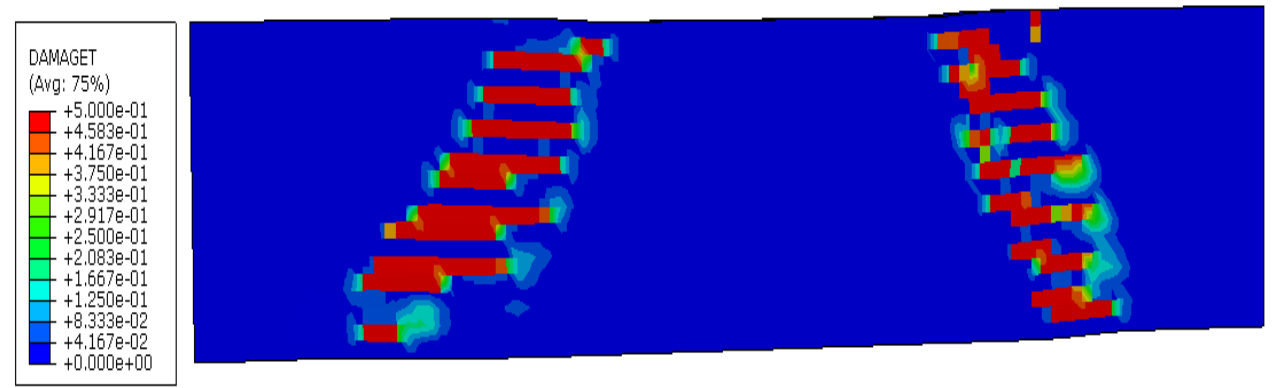

(d)Crack pattern of RAC-10\%RHA-B by FEA

Figure 4. The cracking pattern of RAC-B and RAC-10\%RHA-B 


\subsection{Validation of load versus deflection}

Table 6 shows the maximum deflection of all RAC-RHA beams as documented from experiments and FEA. RAC-B (control beam) recorded highest maximum deflection value while RAC$10 \%$ RHA-B recorded the least deflection value, in both experiments and FEA. From Table 6, it is seen that the maximum deflection obtained from FEA was slightly lesser then the maximum deflection obtained from the experimental results. The percentage difference between FEA and experimental results of maximum deflection are in the range of $5 \%$ to $7.5 \%$. This is in good agreement with the results obtained from previous researches conducted by Charan \& Topdar (2015)[23]; Vilke et al., (2017) [20] and Mendis et al., (2018)[24]. In these studies, the RCC beams containing fibres were analysed by experiment and FEA. The results demonstrated that the deflection obtained from the FEA were $5 \%$ to $15 \%$ less than the experimental analysis.

Load-deflection graphs of RAC -B and RAC-10\%RHA-B beams are presented in Figure 5, and Figure 6, respectively. These graphs show similar load-deflection profiles from experiments and FEA.

Table 6. Maximum deflection of RAC-RHA beam

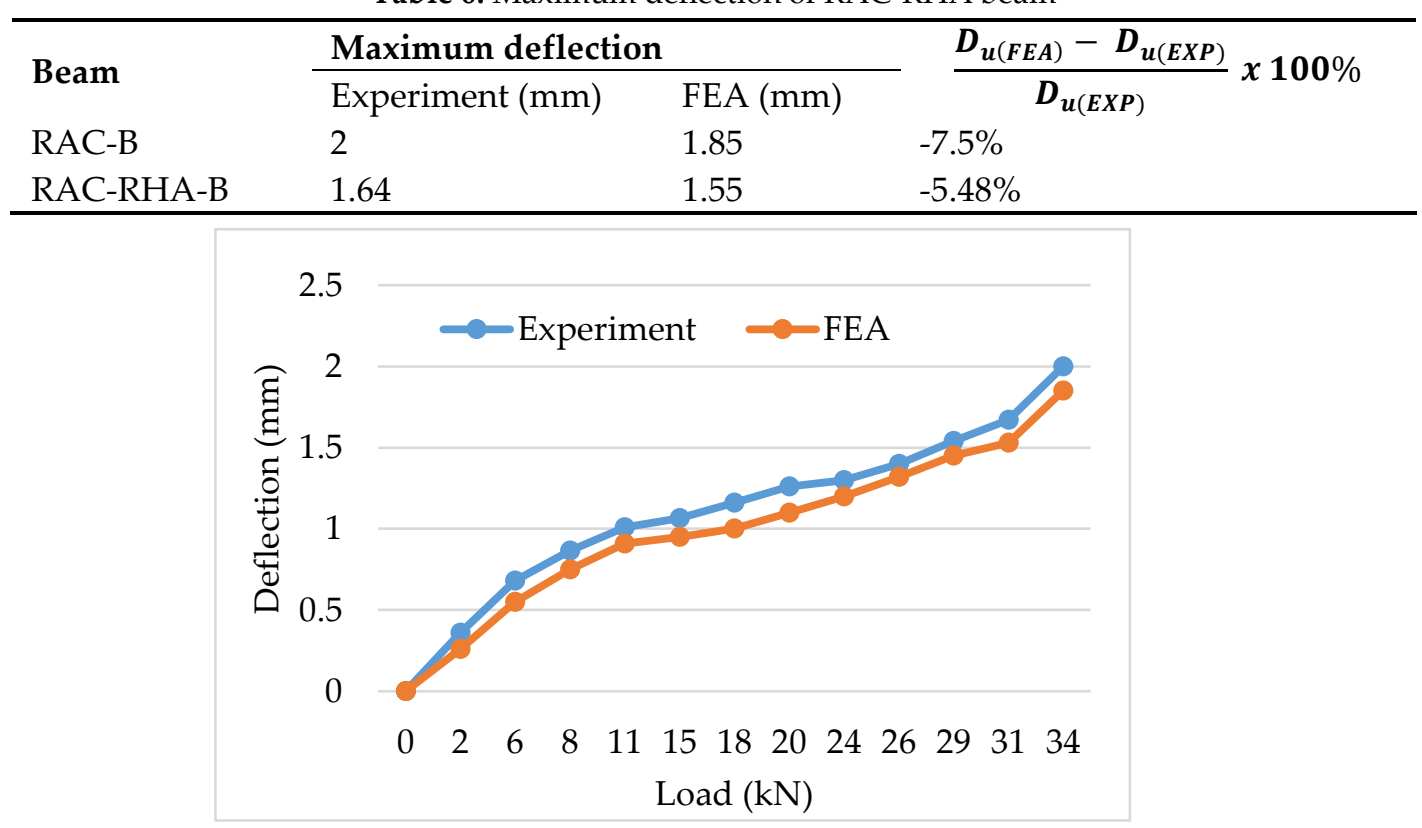

Figure 5. The load deflection profile of control sample RAC-B

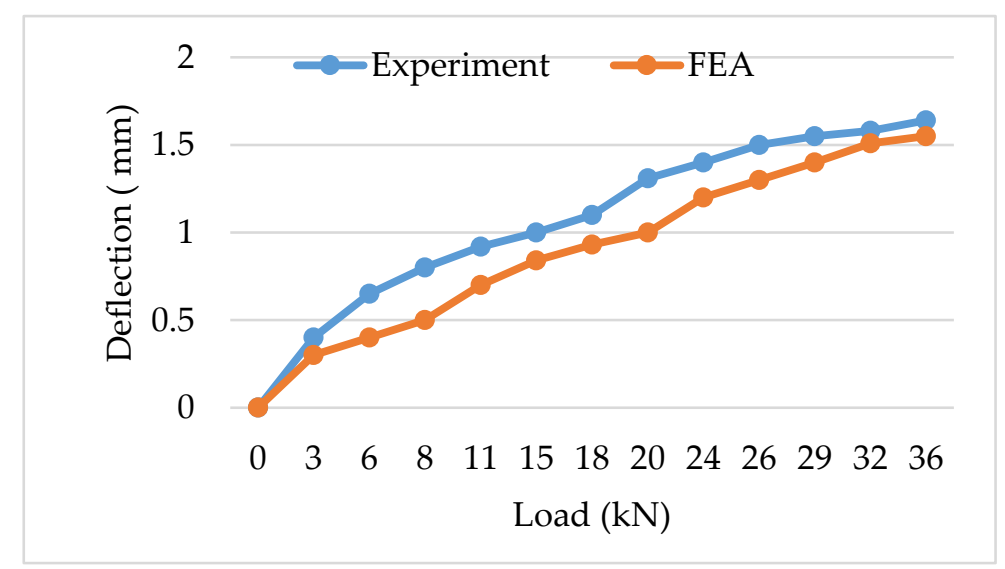

Figure 6: The load deflection profile of RAC- $10 \%$ RHA-B 


\section{Parametric Study:}

The parametric study was conducted to investigate the effect of beam height on failure modes and load deflection profiles of RAC-10\%RHA-B. As the height of the beam greatly influences its structural performance, therefore, it is pertinent to investigate its influence on failure modes and crack patterns. For this purpose, three different beams of depth $300 \mathrm{~mm}, 400 \mathrm{~mm}$ and $500 \mathrm{~mm}$ were investigated.

The impact of different heights on ultimate load, load-deflection pattern and crack profile were analysed. Table 7 demonstrates the structural behaviour of beams with various heights in terms of ultimate load and maximum deflection while all other factors such as, the overall length, width and material characteristics of beam were kept constant.

The results in Table 7 show that the height of beam greatly influences beam strength, and the ultimate strength $(\mathrm{Pu})$, was increased with the increment of beam height. While the maximum deflection decreased with the increment of height. Thus, suggesting direct relation between the height and strength, but inverse relation between height and ductility.

The load-deflection profile of RAC-10\%RHA-B having different depths are shown in Figure 7. It can be seen from the figure that maximum deflection was recorded for beam with $300 \mathrm{~mm}$ height. It performed in the most ductile manner compared to the other beams. Whereas, the lowest deflection was recorded for beam with $500 \mathrm{~mm}$ height. This beam had the most brittle behaviour out of all beam sizes.

The cracking pattern is shown in Figure 8 . The $400 \mathrm{~mm}$ and $500 \mathrm{~mm}$ depth beams were observed to exhibit flexural shear failure mode. Both beams experienced inclined crack at about $30^{\circ}$ from horizontal, appeared from bottom part of the left zone of beam. The crack then initiated to propagate in diagonal direction as it moves towards the upper end of the beam along with the continuation to propagate in length and widen in width. Where as, $300 \mathrm{~mm}$ beam exhibited flexure failure mode where it experienced discontinued straight-line cracks which propagated from the bottom part of beam.

The findings obtained from Abaqus have good agreement with the outcomes found in the previous researches by Metwally et al., (2017) [25] and Jawarkar \& Kadam (2017) [26], which analysed the structural performance of deep beams means of FEA. The outcomes demonstrated that as depth of beam increases ultimate load of reinforced beams increases whereas the deflection of beam decreases.

Table 7. Effects of various depth of beam on ultimate strength and maximum deflection of PSCC-beam

\begin{tabular}{lll}
\hline Beam & $\begin{array}{l}\text { Ultimate Load, } \\
\text { Pu (kN) }\end{array}$ & $\begin{array}{l}\text { Maximum } \\
\text { Deflection } \\
(\mathbf{m m})\end{array}$ \\
\hline RAC-10\%RHA-B-300mm & 42 & 1.87 \\
RAC-10\%RHA-B-400mm & 54 & 1.67 \\
RAC-10\%RHA-B-500mm & 61 & 1.50 \\
\hline
\end{tabular}




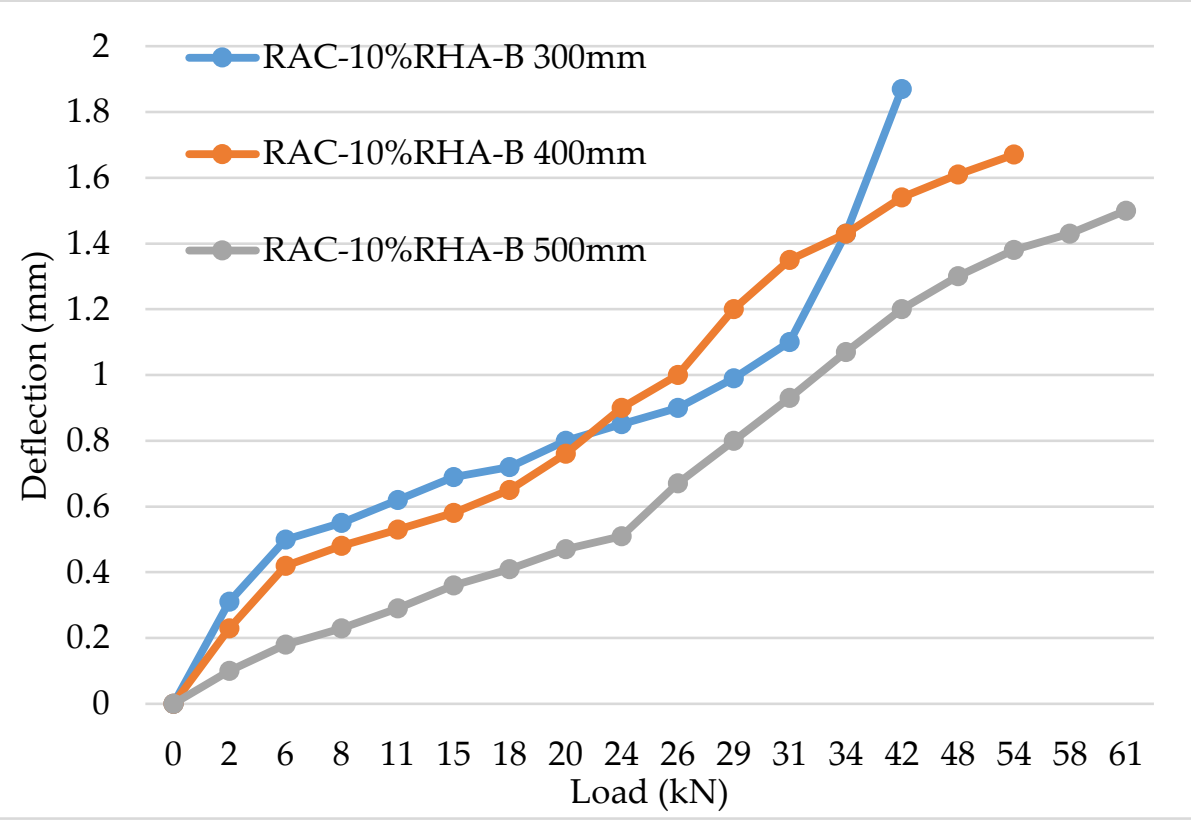

Figure 7. The load deflection profile of control sample RAC- B
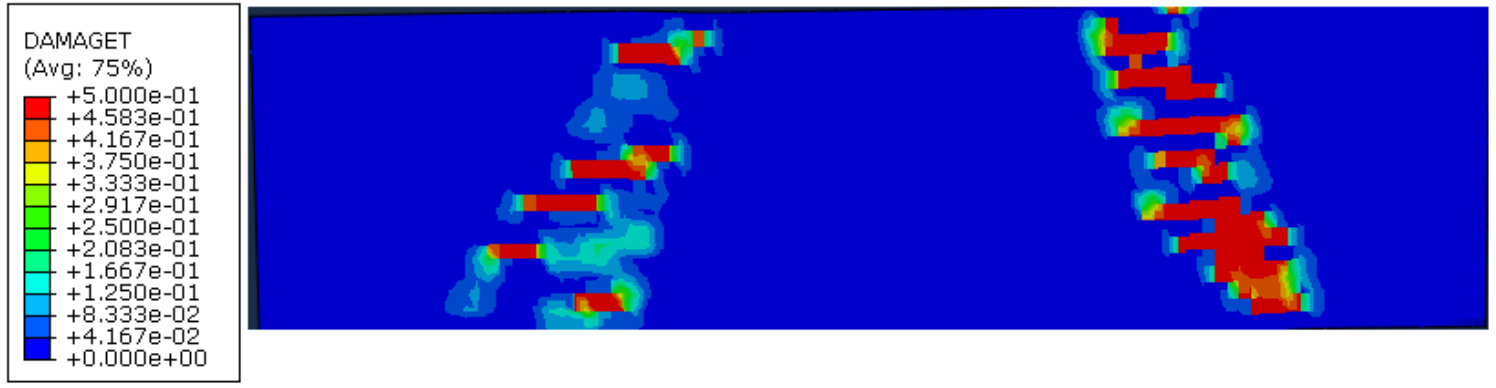

(a) Crack pattern of 500mm RAC-10\%RHA-B
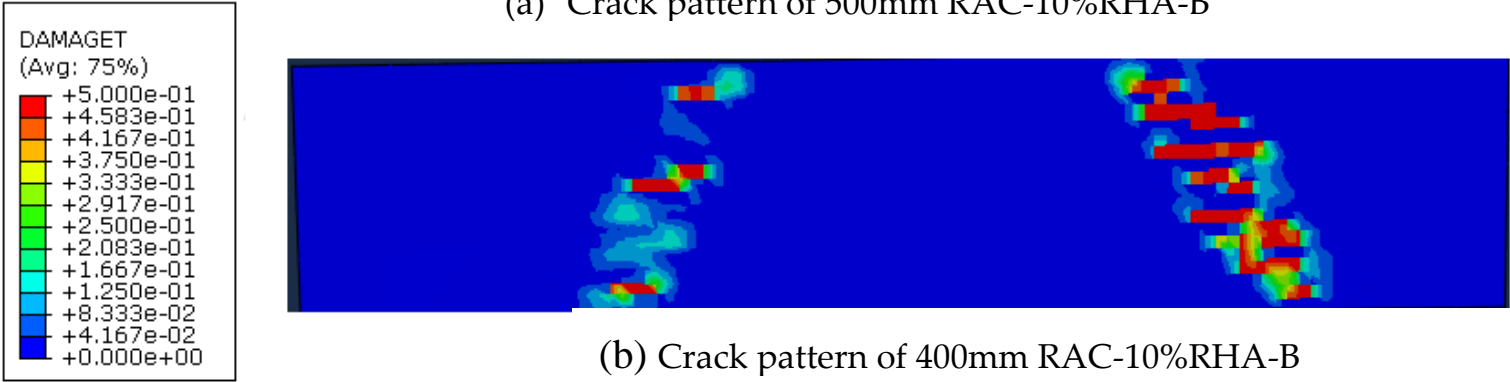

(b) Crack pattern of 400mm RAC-10\%RHA-B
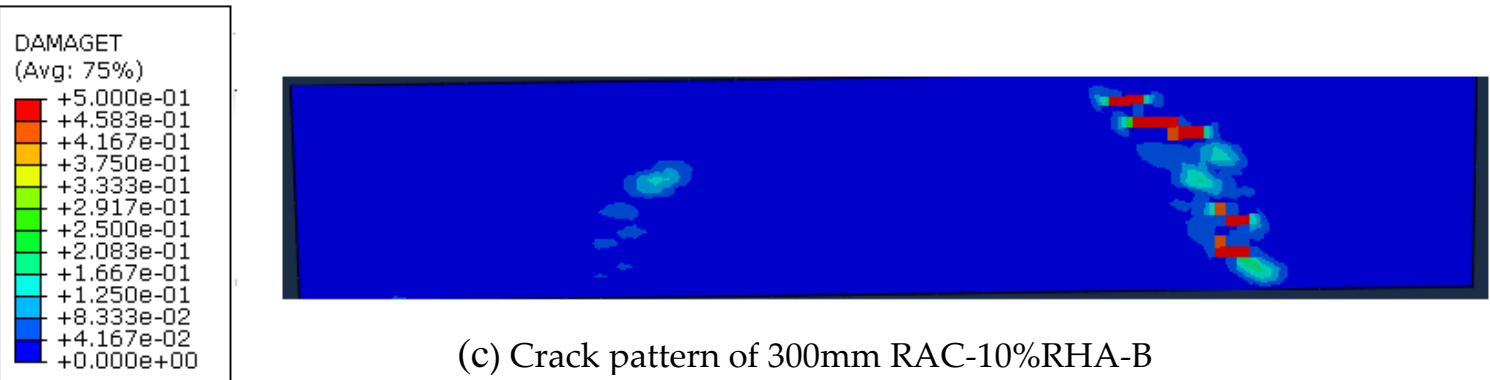

(c) Crack pattern of 300mm RAC-10\%RHA-B

Figure 8. Cracking pattern of RAC-10\%RHA-B with different depths

\section{Conclusion}

Utilization of rice husk ash (RHA) as supplementary cementing material was help to enhance the strength and also contribute to protect the environment from agricultural waste. In this research, RAC-10\%RAC-B model possessed the higher ultimate load and lower deflection values at has higher 
values at $40 \mathrm{kN}$ and $1.64 \mathrm{~mm}$ as compared to control sample (RAC-B) beam at $34 \mathrm{kN} \mathrm{mm} 2 \mathrm{~mm}$ respectively. The FEA results were validated with Laboratorial outcomes. The ultimate load obtained from FEA was $8 \%$ greater than experimental results. Parametric study with different depths has greatly impact on the ultimate load, deflection and cracking pattern. Meanwhile, the failure mechanism were almost similar to the experimental outcomes. However, it could be demonstrated that the Abaqus had capability to predict the structural performance of RAC-10\%RHA-B. Further work on parametric study of foamed concrete is highly recommended with different boundary conditions, beam model dimension and various material properties to overcome financial and time constraint.

Author Contributions: For this research articles four authors were contributed. The details of contributions are provided below;

Mr. Muhammad Tahir Lakhiar and Dr Ather Ali conceived of the presented idea. Mr. Muhammad Tahir Lakhiar developed the theory and performed the computations. Dr Ather Ali and $\mathrm{Mr}$ Muhammad Tarique lakhiar verified the analytical methods. Dr Kong Sih Ying encouraged Mr. Muhammad Tahir Lakhiar to investigate computational analysis of aerated concrete beam and supervised the findings of this work. All authors discussed the results and contributed to the final manuscript.

Conflicts of Interest: All above mentioned authors declare that there is no conflict of interest.

\section{References}

1. Gyurkó, Z., Jankus, B., Fenyvesi, O., \& Nemes, R. Sustainable applications for utilization the construction waste of aerated concrete. Journal of Cleaner Production, (2019) 230, 430-444. https://doi.org/10.1016/i.jclepro.2019.04.357

2. Memon, I. A., Jhatial, A. A., Sohu, S., Lakhiar, M. T., \& Hussain, Z. Influence of fibre length on the behaviour of polypropylene fibre reinforced cement concrete. Civil Engineering Journal, (2018) 4(9), 2124-2131. https://pdfs.semanticscholar.org/333c/638305b03d275077f74b4fe0106dbf94d53c.pdf

3. Zhang, N., Duan, H., Miller, T. R., Tam, V. W., Liu, G., \& Zuo, J. Mitigation of carbon dioxide by accelerated sequestration in concrete debris. Renewable and Sustainable Energy Reviews, (2020), 117, 109495. https://doi.org/10.1016/.rser.2019.109495

4. Han, F., Luo, A., Liu, J., \& Zhang, Z. Properties of high-volume iron tailing powder concrete under different curing conditions. Construction and Building Materials, (2020)., 241, 118108. https://doi.org/10.1016/j.conbuildmat.2020.118108

5. He, X., Zheng, Z., Ma, M., Su, Y., Yang, J., Tan, H., ... \& Strnadel, B. New treatment technology: The use of wet-milling concrete slurry waste to substitute cement. Journal of Cleaner Production, (2020), 242, 118347. https://doi.org/10.1016/j.jclepro.2019.118347

6. Jhatial, A. A., Goh, W. I., Mohamad, N., Hong, L. W., Lakhiar, M. T., Samad, A. A. A., \& Abdullah, R. The Mechanical Properties of Foamed Concrete with Polypropylene Fibres. International Journal of $\begin{array}{lllll}\text { Engineering } & \& & \text { Technology, (2018), } & 7(3.7), & 411-413 .\end{array}$ https://www.researchgate.net/profile/Ashfaque Thatial/publication/327427365 
7. Keerio, M. A., Lakhiar, M. T., \& Sohu, S. Comparative Study on Flexural Performance of Foamed Concrete Beam Containing Plastic Fibres. International Journal of Sustainable Construction Engineering and Technology, (2019) 10(1), pp. 10-18.

a. https://publisher.uthm.edu.my/ojs/index.php/IJSCET/article/view/3569

8. Kamaruddin, S., Goh, W. I., Jhatial, A. A., \& Lakhiar, M. T. Chemical and Fresh State Properties of Foamed Concrete Incorporating Palm Oil Fuel Ash and Eggshell Ash as Cement Replacement. International Journal of Engineering $\mathcal{E}$ Technology, (2018), 7(4.30), 350-354. https://www.researchgate.net/profile/Ashfaque_Jhatial/publication/329450930

9. Habib, A., Begum, H. A., \& Hafiza, E. R. Study on production of Aerated concrete block in Bangladesh. International Journal of Innovative Science, Engineering and Technology, (2015), 2, 200-203.

a. https://www.researchgate.net/profile/Ahsan_Habib14/publication/274639775

10. He, X., Zheng, Z., Yang, J., Su, Y., Wang, T., \& Strnadel, B. Feasibility of incorporating autoclaved aerated concrete waste for cement replacement in sustainable building materials. Journal of Cleaner Production, (2020). 250, 119455. https://doi.org/10.1016/j.jclepro.2019.119455

11. Raj, A., Borsaikia, A. C., \& Dixit, U. S. Manufacturing of Autoclaved Aerated Concrete (AAC): Present Status and Future Trends. In Advances in Simulation, Product Design and Development, (2020) (pp. 825833). Springer, Singapore. https://doi.org/10.1016/j.conbuildmat.2019.117721

12. Mohamad, N., Lakhiar, M. T., Samad, A. A. A., Mydin, M. A. O., Jhatial, A. A., Sofia, S. A., ... \& Ali, N. Innovative and sustainable green concrete-A potential review on utilization of agricultural waste. In IOP Conference Series: Materials Science and Engineering (2019, August), (Vol. 601, No. 1, p. 012026). IOP Publishing. https://iopscience.iop.org/article/10.1088/1757-899X/601/1/012026/meta

13. Mohamad, N., Samad, A. A. A., Lakhiar, M. T., Mydin, M. A. O., Jusoh, S., Sofia, A., \& Efendi, S. A. Effects of Incorporating Banana Skin Powder (BSP) and Palm Oil Fuel Ash (POFA) on mechanical properties of lightweight foamed concrete. International Journal of Integrated Engineering, (2018), 10(9), pp 101-109. .https://publisher.uthm.edu.my/ojs/index.php/ijie/article/view/3104

14. Vishwakarma, V., \& Uthaman, S. Environmental impact of sustainable green concrete. In Smart Nanoconcretes and Cement-Based Materials, (2020). (pp. 241-255). Elsevier. https://doi.org/10.1016/B978-012-817854-6.00009-X

15. Das, S. K., Singh, S. K., Mishra, J., \& Mustakim, S. M. Effect of Rice Husk Ash and Silica Fume as Strength-Enhancing Materials on Properties of Modern Concrete-A Comprehensive Review. In Emerging Trends in Civil Engineering, (2020), (pp.253-266). Springer, Singapore. https://link.springer.com/chapter/10.1007/978-981-15-1404-3 21.

16. Rahman, A. F., Goh, W. I., Mohamad, N., Kamarudin, M. S., \& Jhatial, A. A. Numerical analysis and experimental validation of reinforced foamed concrete beam containing partial cement replacement. Case Studies in Construction Materials, (2019), 11, e00297.

17. Wang, Z., Yang, Z., Yang, Y., \& Xian, G. Flexural fatigue behavior of a pultruded basalt fiber reinforced epoxy plate subjected to elevated temperatures exposure, Polymer Composites, (2018), 39(5), pp. 17311741. 
18. Sjaarda, M., Walbridge, S., \& West, J. S. Assessment of Shear Connection through Composite Beam Modeling. Transportation Research Record, (2018), 3, pp. 1-9.

19. Murthy, A. R., Karihaloo, B. L., Rani, P. V., \& Priya, D. S. Fatigue behaviour of damaged RC beams strengthened with ultra-high-performance fibre reinforced concrete. International Journal of Fatigue, (2018) 116, pp. 659-668.

20. Vilke, T. G. Structural performance of a prefabricated concrete beam with longitudinal cavities. University of Stavanger, (2017) Norway: Master's Thesis.

21. Wahalathantri, B. L., Thambiratnam, D. P., Chan, T. H. T. \& Fawzia, S. A material model for flexural crack simulation in reinforced concrete elements using ABAQUS. Proceedings of the first international conference on engineering, designing and developing the built environment for sustainable wellbeing. Queensland University of Technology: QUT e prints. (2011), pp. 260-264.

22. Sihua, D., Ze, Q. \& Li, W. Nonlinear Analysis of Reinforced Concrete Beam Bending Failure Experimentation Based on ABAQUS. Analysis, (2015). 73, pp. 10-16.

23. Charan, B. \& Topdar, P., On Finite Element Analysis of Steel and RC Beams: Performance of Different Elements, Journal of Mechanical and Civil Engineering, (2015), 2, pp. 13-18.

24. Mendis, A. S., Al-Deen, S., \& Ashraf, M. Flexural shear behaviour of reinforced Crumbed Rubber Concrete beam. Construction and Building Materials, (2018), 166, pp. 779-791.

25. Metwally, I. M. Three-dimensional nonlinear finite element analysis of concrete deep beam reinforced with GFRP bars. HBRC journal, (2017), 13(1), pp. 25-38.

26. Jawarkar, V. S., \& Kadam, K. N., Finite Element Analysis of Reinforced Concrete Deep Beams with Large Openings. International Journal of Innovative Research in Science, Engineering and Technology, (2017), 6(1), pp. 690-697. 